\title{
Educaçáo, sustentabilidade e justiça social: uma análise epistemológica do pensamento de Hans Jonas e Edgar Morin
}

\author{
Helena Maria Ferreira ${ }^{1}$ \\ https://orcid.org/0000-0002-8749-5426 \\ Joel Cezar Bonin ${ }^{2}$ \\ https://orcid.org/0000-0003-0437-7609 \\ Leticia Carreńo-Saucedo ${ }^{3}$ \\ https://orcid.org/0000-0002-9221-6620
}

\section{Resumo}

Este artigo ensaístico elege como objeto de estudo o processo educativo em uma perspectiva que articula o princípio da ética da responsabilidade e o princípio da complexidade. Nesse contexto, o objetivo precípuo deste texto é refletir acerca da articulação das ideias de dois pensadores - Hans Jonas e Edgar Morin - que são basilares para uma educação que busca promover a transformaçáo efetiva dos modos de pensar e de agir dos sujeitos-cidadãos. Assim, a partir de uma reflexão teórica, este trabalho questiona a visão utilitária predominante na ordem política e social do mundo moderno, que atribui à escola o papel de ensinar conteúdos em detrimento de uma formação para uma vida saudável e ética na sociedade. Metodologicamente, este artigo apresenta um panorama do princípio da responsabilidade de Hans Jonas e uma explanação que contempla dois saberes necessários à vida humana propostos por Edgar Morin: ensinar a compreensão e a ética do gênero humano. A partir desses princípios, desenvolve-se uma reflexáo propositiva, em que se defende a posição de que a Educaçáo constitui um processo integral de formaçáo humana, pois cada ser humano precisa construir o seu modo de vida, tendo por base o compromisso ético com a natureza, a responsabilidade por suas ações e a compreensão das potencialidades de promoção da justiça social por parte de cada cidadão.

Palavras-chave: Educação e formação humana, Educação e sujeito ético, Autonomia e educação, Educação e liberdade, Educação e justiça social.

\footnotetext{
${ }^{1}$ Professora da Universidade Federal de Lavras, Departamento de Estudos da Linguagem. Atua como docente no Programa de Pós-graduação em Letras e no Programa de Pós-graduaçăo em Educação. Doutora em Linguística Aplicada e Estudos da Linguagem (PUC-SP) - E-mail: helenaferreira@ufla.br.

2 Professor da Universidade Alto Vale do Rio do Peixe - UNIARP (Caçador-SC). Atua como docente no Programa de Pós-graduaçáo - Mestrado Profissional em Educaçáo Básica (PPGEB). Doutor em Filosofia pela PUC-PR. E-mail: joel@uniarp.edu.br.

${ }^{3}$ Profesora investigadora de Tiempo Completo de la Universidad Autonoma del Estado de México. Unidad Académica Profesional Tejupilco - Dra. en Psicologia (PhD). E-mail: psicoletty@hotmail.com.
} 


\section{Education, sustainability and social justice: an epistemological analysis of the thinking of Hans Jonas and Edgar Morin}

\section{Abstract}

This essay article chooses the educational process as an object of study in a perspective that articulates the principle of responsibility ethics and the principle of complexity. In this context, the main objective of this text is to reflect on the articulation of the ideas of two thinkers Hans Jonas and Edgar Morin - that are basic to an education that seeks to promote the effective transformation of the ways of thinking and acting of the subject-citizens. Thus, from a theoretical reflection, this work questions the utilitarian view prevalent in the political and social order of the modern world, which attributes to the school the role of teaching content at the expense of training for a healthy and ethical life in society. Methodologically, this article presents an overview of Hans Jonas' principle of responsibility and an explanation that includes two knowledge necessary for human life proposed by Edgar Morin: teaching the understanding and ethics of mankind. Based on these principles, a propositional reflection is developed, in which the position that education constitutes an integral process of human formation is defended since each human being needs to build his / her way of life, based on the ethical commitment to nature, the responsibility for their actions and the understanding of the potential of promoting social justice by each citizen.

Keywords: Education and human formation, Education and ethical subject, Autonomy and education, Education and freedom, Education and social justice.

\section{Introduçáo}

No contexto contemporâneo, a problematizaçáo inerente às práticas educativas abarca a discussão acerca fragmentação dos conhecimentos, expressa nos currículos lineares e a dissociação entre os conteúdos escolares e a vida cotidiana. Embora se possa antever avanços substanciais na ressignificação dos processos de ensino e de aprendizagem, a questão da articulação efetiva entre educação, sustentabilidade e justiça social ainda demanda incursóes teóricas, epistemológicas e axiológicas que possam dar conta da complexidade do processo educativo e suas potencialidades para a formação cidadá.

Nesse sentido, a questão que norteia este artigo emerge dos estudos desenvolvidos por González Velasco (2017, 2018), Petraglia (2008, 2013), Zwierewicz (2013, 2017), Zwierewicz e Torre (2009), que destacam a importância de uma educação que, sob a perspectiva do pensamento complexo, considere a multidimensionalidade do sistema educacional, de modo a considerar a articulação com outros sistemas, que dialogicamente, $o$ complementam, o influenciam e também são complementados e influenciados. 
Assim, em uma abordagem propositiva, o presente artigo busca ampliar a discussão proposta pelos pesquisadores supracitados, engendrando uma articulação entre o princípio da ética da responsabilidade e o princípio da complexidade, a partir das ideias de Hans Jonas e Edgar Morin - que são basilares para uma educação que busca promover a transformação efetiva dos modos de pensar e de agir dos sujeitos-cidadãos.

Para a consecução do objetivo proposto, este trabalho apresenta os pressupostos relativos ao princípio da responsabilidade (proposta de Hans Jonas) e à educação para o futuro (proposta de Edgar Morin), com vistas a fundamentar uma discussão acerca da articulação entre educação, sustentabilidade e justiça social.

Para essa articulação, é relevante pontuar que a concepção de complexidade deve ser tomada como referência. Segundo Morin (2000), o termo "complexus" emana uma tessitura, ou seja, "há complexidade quando elementos diferentes são inseparáveis constitutivos do todo (como o econômico, o político, o sociológico, o psicológico, o afetivo, o mitológico)". Além disso, o autor pontua que "há um tecido interdependente, interativo e inter-retroativo entre o objeto de conhecimento e seu contexto, as partes e o todo, o todo e as partes, as partes entre si." (p. 38).

Nesse contexto, parte-se do pressuposto de que vivência em sala de aula não se apresenta dissociada da vida na sociedade, desse modo, as práticas educativas devem incidir sobre a formação ética e responsável, com uma obrigação incondicional da existência humana. De acordo com Jonas (2006, 177), "a existência da humanidade significa simplesmente que vivam os homens".

A partir dos princípios de responsabilidade ética e complexidade, este artigo problematiza os antagonismos nos processos educativos, ou seja, "de um lado, os saberes desunidos, divididos, compartimentados e, de outro, as realidades ou problemas cada vez mais multidisciplinares, transversais, multidimensionais, transnacionais, globais e planetários". (p. 36). Enfim, este artigo questiona a visão utilitária predominante na ordem política e social do mundo moderno, que atribui à escola o papel de ensinar conteúdos em detrimento de uma formação para uma vida saudável e ética na sociedade.

A tarefa da educação é produzir e socializar o conhecimento com a capacidade de questionar o próprio conhecimento. Nessa direção, produzir ciência e tecnologia implica buscar a melhoria da qualidade de vida, individual e coletiva. A busca pelo conhecimento exige lutar contra suas próprias ideias e valores, implica pautar-se na responsabilidade ética e no saber compreender a dimensão humana e planetária. 


\section{Hans Jonas e o princípio responsabilidade}

O filósofo Hans Jonas (1903-1993) apresenta uma compreensão sobre a realidade fortemente orientada a repensar o mundo e as ações humanas e suas respectivas consequências, de modo mais pormenorizado, sob a perspectiva de uma ética voltada para a coletividade. Nesse escopo, o filósofo propóe uma reflexão acerca dos problemas advindos dos avanços tecnológicos e seus impactos no desenvolvimento da vida em escala planetária.

A obra de Hans Jonas destaca entre os filósofos contemporâneos, em função de suas preocupações não serem metafísicas (apesar de não abandonalas), mas por serem concretas e evidentemente muito prementes. Sua preocupação náo é essencialmente pedagógica, mas ela está revestida de um aspecto demasiadamente olvidado, a saber, o viés ético. Segundo ele, há uma correlação muito forte entre o saber científico e o esquecimento ético. A supervalorização de saberes orientados apenas para a concentração de uma ideia de poder não tornou a vida humana melhor, a não ser para uma minoria. Aliás, vale a pena ressaltar que o saber científico usa a natureza, na maioria das vezes, sem medir as consequências. Por isso, em seu texto, Jonas diz:

Primeiro, esse saber "neutralizou" a natureza sob o aspecto do valor; em seguida foi a vez do homem. Agora trememos na nudez de um niilismo no qual o maior dos poderes se une ao maior dos vazios; a maior das capacidades, ao menor dos saberes sobre para que utilizar tal capacidade. Trata-se de saber se, sem restabelecer a categoria do sagrado, destruída de cabo a rabo pelo Aufklärung (Iluminismo) científico, é possível ter uma ética que possa controlar os poderes extremos que hoje possuímos e que nos vemos obrigados a seguir conquistando e exercendo. [...] Mas uma religião inexistente não pode desobrigar a ética de sua tarefa; da religiáo pode-se dizer que ela existe ou não existe como fato que influencia a ação humana, mas no caso da ética é preciso dizer que ela tem que existir. Ela tem de existir porque os homens agem, e a ética existe para ordenar suas ações e regular seu poder de agir. Sua existência é tanto mais necessária, portanto, quanto maiores forem os poderes de agir que ela tem de regular. (JONAS, 2006, p. 65-66).

Aqui vemos uma questão fundamental da pesquisa de Jonas: compreender por que a ética foi esquecida no processo avassalador do acúmulo de saberes científicos? Todos os seres humanos se constituem como seres de/em ação e a ética deve dar as coordenadas fundamentais desse agir. Nesse 
ponto, consideramos que Jonas aponta que o agir humano é imprescindível da condição humana, tanto quanto o conhecimento. Mas é preciso estabelecer o saber/conhecimento sob critérios claros de orientação, pois o ser humano ávido pelo conhecimento, muitas vezes, se vê cego sobre os resultados e os encaminhamentos que esse saber pode despender.

\section{Por uma ética da responsabilidade}

Para Jonas, ética e responsabilidade em nossos dias devem coadunar em uma nova sinonímia. Dessa maneira, ele mostra que é preciso colocar na balança das equaçôes a ação humana e a ética. Agir é um dado a priori, o resultado da ação, por sua vez, é a posteriori. O problema é que, por vezes, não se sabe ao certo qual será o rumo do a posteriori. Desse modo, para Jonas, é preciso método, deveres ou, até mesmo, mandamentos que apontem qual é a verdadeira direção que o ser humano deve tomar na medida em que age. Essa direção, por sua vez, não deve desviar-se da ética. Contudo, um dos dilemas que perpassam os atos humanos resvala no problema do tecnicismo, ou seja, as pessoas podem agir de acordo com normativas morais/éticas sem o exercício do autoquestionamento. O exercício ético é sempre um exercício de indagação, de questionamento. Saber as razões porque se age é tão importante quanto a própria ação. Sobre isso, Jonas afirma que:

[...] o reconhecimento do malum é infinitamente mais fácil do que do bonum; é mais imediato, mais urgente, bem menos exposto a diferenças de opiniâo; acima de tudo, ele não é procurado: o mal nos impõe a sua simples presença, enquanto o bem pode ficar discretamente ali e continuar desconhecido, destituído de reflexão (esta pode exigir uma razão especial). Não duvidamos do mal quando com ele nos deparamos; mas só temos certeza do bem, no mais das vezes, quando dele nos desviamos. É de se duvidar que alguém, alguma vez, tenha feito o elogio da saúde sem pelo menos ter visto o espetáculo da doença, o elogio da decência sem ter encontrado a patifaria, e o da paz sem conhecer a miséria da guerra. O que nós não queremos, sabemos muito antes do que aquilo que queremos. (JONAS, 2006, p. 71).

Em outras palavras, isso significa dizer que o exercício da ação precisa passar por um exercício de descoberta, de investigação e, nas palavras de Jonas, de heurística. Saber como agir é um exercício de distinção entre certo e errado, bem e mal, profano e sagrado, adequado e inadequado. Como o autor pontua: 
[...] Náo saberíamos sobre a sacralidade da vida caso não houvesse assassinatos e o mandamento "não matarás" não revelasse essa sacralidade, e não saberíamos o valor da verdade se não houvesse a mentira, nem o da liberdade sem a sua ausência, e assim por diante, assim também, em nosso caso, na busca de uma ética da responsabilidade a longo prazo [...] nos auxilia antes de tudo a previsão de uma deformação do homem, que nos revela aquilo que queremos preservar no conceito de homem. [Assim] embora, portanto, a heurística do medo não seja a última palavra na procura do bem, ela é uma palavra útil (JONAS, 2006, p. 70-71).

Diante disso, nos cabe um breve resumo da situação apresentada e enfrentada por Hans Jonas no quesito ético a partir da escrita de Oliveira, um dos maiores especialistas do autor alemão no Brasil:

A base dessa nova exigência ética é o diagnóstico dos efeitos ou consequências do poder tecnológico que deu ao homem não só a possibilidade de alterar o futuro, mas até mesmo de inventá-lo ou interditá-lo por completo - tamanho o risco evocado por esse novo poder, magnânimo e ambivalente, diante do qual a vida se revela frágil e vulnerável, algo nunca antes tematizado no campo ético-filosófico. É a novidade do cenário tecnológico moderno que traz, portanto, o futuro para o centro da reflexão ética, no que tange ao porvir do homem e da natureza. [...] (OLIVEIRA, 2012, p. 389).

Ainda segundo Oliveira, o dilema que enfrentamos em nossa atualidade é corolário de um modo unilateral de enfrentamento da realidade, a saber, o enfrentamento ausente de uma preocupação com o futuro. Esse futuro é, na verdade, um agravamento recrudescido da técnica voltada apenas para a consecução de interesses do "presente" sem ter em vista o futuro. É um agora momentâneo, circunstancial, inédito que não consegue visualizar à longo prazo suas consequências nefastas e deletérias. Em outras palavras, essa visão de mundo cria uma forma educativa muito peculiar: a extirpação de um olhar para além de nós mesmos. É como se o mundo fosse marcado por uma visão demasiadamente pragmática e utilitarista. Esse excesso de pragmatismo tem resultado em problemas sérios do ponto de vista da desigualdade social, do desequilíbrio ambiental e da restrição do acesso à bens sociais de uso comum como a educação, a saúde, o saneamento básico e a segurança.

Aliás, tais constatações podem ser comprovadas de várias formas em nossa atualidade. Um exemplo claro foi a crise hídrica do estado de São Paulo entre 2014 e 2016, que confirmou a hipótese de que só sabemos a importância de um bem (nesse caso, natural) na sua ausência. Outro exemplo é a incidência 
cada vez maior de casos de doenças de verão (dengue, zika, coronavírusCOVID-19 e outras) que denotam ainda mais o fato de que só podemos saber o valor da saúde na doença.

Além disso, do ponto de vista tecnológico, a avalanche de produtos novos e com vida útil bem curta nos levam a pensar: o que fazer com tanto lixo tecnológico? Qual será a consequência negativa do acúmulo de bens materiais diante de sua rápida obsolescência?

Assim, vê-se que as consequências futuras de nossas açóes presentes devem ser o principal instrumento de avaliação de nossas condutas e de que como estamos pensando a educação como um todo. Dito isso, sermos capazes de investigar o nosso próprio modo de ação diante dos outros e do mundo é um dos principais indicadores de autoavaliação. Deve-se pensar a educação com vistas para o presente e para o futuro. Nossa maneira de viver e nossa visão de mundo revelam se somos realmente capazes de repensar o grau de responsabilidade que temos conosco e com aqueles que virão.

Por isso, Jonas é incisivo no que se refere à formulação de um novo imperativo ético:

um imperativo adequado ao novo tipo de agir humano e voltado para o novo tipo de sujeito atuante deveria ser mais ou menos assim: 'Aja de tal modo a que os efeitos da tua ação sejam compatíveis com a permanência de uma autêntica vida humana sobre a Terra [Assim, este] novo imperativo diz que podemos arriscar a nossa própria vida, mas não a da humanidade. [...] Nós não temos o direito de escolher a nãoexistência de futuras geraçôes em função da existência atual, ou mesmo de as colocar em perigo. (JONAS, 2006, p. 47-48).

Isto posto, podemos compreender agora o quanto a ética de Jonas está voltada para um aspecto educacional e pedagógico. É preciso um novo modo de compreensão da vida e isto passa pelo problema não apenas da educação das crianças, mas pela reeducação dos adultos. Cremos que aqui pode-se pensar sobre a inculcaçáo de novos modos de pensar e agir. Nessa perspectiva, Patrice Canivez nos fala sobre a importância do habitus: “[...] Contrair um hábito, mesmo que seja pelo contato com um estilo ou com um método de ensino é, pois "interiorizar" um certo valor, assimilar um princípio de ação e de apreciação" (CANIVEZ, 1991, p. 53).

Por isso, trata-se de expor que a educação precisa relacionar hábitos e comportamentos que, por sua vez, estão diretamente ligados à ideia de "ethos", de ética, de prática e de ação. Esses hábitos podem e devem ser ensinados. Não apenas pelo viés da imposição, mas pela mediação entre 
professores, pais e alunos. O olhar pedagógico fundado em uma perspectiva filosófica de "repensar o hoje tendo como telos o amanhã" é a principal proposta de Hans Jonas. Falta, contudo, a sua verdadeira efetivação.

Dessa forma, podemos aqui apresentar a ideia de que Hans Jonas e Patrice Canivez possuem uma ligação muito forte quando o tema ética e educação se mostram em evidência, na medida em que assumir uma postura ética diante do mundo é uma forma de assumir uma postura educativa. Tal postura, em outras palavras, significa ter um senso crítico aguçado para avaliar e "calcular o mundo e suas falsas obviedades" e ter, ao mesmo tempo, uma visão de mundo abrangente, capaz de incluir o cuidado consigo mesmo e com o mundo:

$\mathrm{O}$ indivíduo que calcula sua conduta não é ainda o indivíduo que pensa, que equaciona corretamente o problema da justiça, do direito, da liberdade, de uma política racional. [...] Um mundo de puro cálculo, reduzido a regras de produção, de trocas e de consumo, seria decerto inabitável. [Contudo], assim mesmo, a difusão desses comportamentos, desses hábitos, dessa maneira racional e calculista de trabalhar torna possível a reflexáo [...]. Porque o senso de eficácia, de autonomia e de cálculo é, no fundo, um senso crítico. É portador de uma desconfiança para com autoridades puramente tradicionais, de uma exigência de racionalidade e de certa capacidade para perceber os objetivos concretos de uma política. (CANIVEZ, 1991, p. 75)

Dito de outro modo, quanto mais uma pessoa aperfeiçoa o seu senso crítico, mais ela se torna capaz de se apoderar (empowerment) de um saber que não tem a função de controlar a natureza, o mundo e o outro, mas em transformá-la cada vez mais para ver o mundo com clareza e agudeza. Nesse sentido, vê-se a junçáo do cuidado do apoderamento do saber tendo em vista uma vida mais ética e uma capacidade de calcular e avaliar as próprias açóes com mais aclaramento/esclarecimento, pois essa é a verdadeira Aufklärung que Jonas e Canivez defendem: a educação para a vida.

Até aqui, discorreu-se sobre as ideias fundamentais de Hans Jonas e a articulação de seu pensamento com alguns comentadores que defendem seu ponto de vista ou que dialogam com suas ideias. Assim sendo, em função da amplitude de seus argumentos, considera-se que Jonas é um grande interlocutor do princípio responsabilidade. Por esse prisma, entende-se que tal princípio é perfeitamente capaz de interligar-se com o pensamento de muitos autores contemporâneos que defendem uma educação libertadora focada na sustentabilidade planetária e numa visão ecoformadora, capaz de 
sensibilizar o olhar para um mundo educacional prenhe de justiça social e equidade, entre eles se destacam: González Velasco (2017, 2018), Petraglia (2008, 2013), Zwierewicz (2013, 2017), Zwierewicz e Torre (2009). Esses autores embasam suas discussões em Edgar Morin e propõem uma educação a partir da vida e para a vida, o que implica construir conexóes entre as várias ramificaçóes da ciência e relaçóes com a vida planetária.

Nessa dimensão, inspirados nas pesquisas dos autores supracitados e para coadunar com o posicionamento de Jonas e seu princípio da responsabilidade ética, dois princípios discutidos na obra Os Sete Saberes necessários à Educação do Futuro, de Edgar Morin, foram selecionados para a discussão aqui proposta. Assim, no próximo item, apresentar-se-ão as ideias principais do autor e sua importância para o diálogo com Hans Jonas.

\section{Edgar Morin e uma educaçáo para o futuro}

O pensamento complexo, fruto das pesquisas de Morin, pode ser resumido do seguinte modo:

A complexidade está presente na integração e desintegração do universo. De acordo com Morin, viver e morrer são partes do mesmo complexo biológico da vida dos seres, sendo argumentado pelo autor que desde a origem da vida, muito mais espécies pereceram do que se mantiveram vivas, sendo inserida inclusive a paradoxal e célebre frase de Heráclito "viver de morte, morrer de vida" [...]. Assim, de acordo com o autor, a multidisciplinaridade faz parte da construção/desconstrução, organização/desorganização, viver/morrer do universo, sendo muito pobre a vida unidisciplinar, fragmentada e ordenada. (PIMENTA, 2013, p. 35).

Assim, num primeiro momento, podemos afirmar que o pensamento de Morin nos impulsiona para uma análise muito diferenciada sobre o mundo educativo: pensar a educação significa pensar a ideia de ruptura e descontinuidade, justamente, porque Morin parte do princípio heraclitiano de compreensão do mundo. Tal ideia pode ser aceita com a anuência da premissa de que toda forma de saber é uma forma de aceitação dos saberes "em movimento" e não em situações estanques e definidas antes da experiência. Aliás, o princípio da complexidade, segundo a perspectiva de Morin, se assemelha com a noção de que todo saber se póe numa situação de relação e não de imposição hierárquica, na qual alguns saberes estão acima dos 
outros. Essa ideia nos remete a noção de total intercambialidade entre os saberes e não de superioridade versus inferioridade de conhecimentos.

Dessa maneira, podemos dizer que a partir da ideia dos saberes necessários à educação do futuro, Morin demonstra essa ideia de intercambialidade com maior clareza apontando a complexidade e a necessidade dialógica entres os saberes para a existência de um futuro para a educaçáo e para a humanidade como um todo. A partir desses saberes, depreende-se que a educação, não obstante, é um tema que diz respeito a todos os cidadãos, pois como foi discutido por Hans Jonas, a formação educativa é um problema de caráter endocultural, ou seja, educar e educar-se é um processo de aquisição e de compreensão dos saberes que perdura por toda a vida. Dessa maneira, todos os saberes se tornam importantes na medida que estão em posição de relação com a vida em sua complexidade. Assim sendo, o pensamento complexo se torna uma chave de leitura do mundo e uma "matriz interpretativa" suficientemente capaz de assimilar o mundo do modo mais abrangente possível.

Diante disso e, tendo em vista os critérios selecionados para a produção de nosso trabalho, deseja-se apresentar, de modo mais cirúrgico nesse momento, o pensamento de Morin a partir de alguns saberes específicos (sexto saber - ensinar a compreensão e sétimo saber - a ética do gênero humano), em função da perspectiva da possível correlação do pensamento de Morin com o pensamento de Hans Jonas. Outrossim, é fundamental lembrar que a relação entre os dois autores se dá em virtude da capacidade que ambos possuem de terem captado o ZeitGeist ${ }^{4}$ da segunda metade do século XX e de apresentarem com grande precisão os dilemas de um mundo marcado por novas tecnologias (internet, computadores e celulares) e por antigas preocupaçóes (o futuro do mundo, da educaçáo e da vida como um todo).

\section{O sexto saber: ensinar a compreensáo}

Para Edgar Morin (2002), é fundamental se considerar o contexto social no qual estamos embarcados:

A situação é paradoxal sobre a nossa Terra. As interdependências multiplicaram-se. A consciência de ser solidários com a vida e a morte,

\footnotetext{
${ }^{4}$ A ideia de ZeitGeist representa o espírito de uma época ou de um tempo. É a maneira de compreender e captar as experiências de um determinado momento histórico. Dessa maneira, Hans Jonas e Edgar Morin podem ser bons intérpretes desse momento histórico que estamos vivendo no limiar do século XXI.
} 
de agora em diante, une os humanos uns aos outros. A comunicação triunfa, o planeta é atravessado por redes, fax, telefones celulares, modems, Internet. Entretanto, a incompreensão permanece geral. Sem dúvida, há importantes e múltiplos progressos da compreensão, mas o avanço da incompreensão parece ainda maior. (MORIN, 2002, p. 93)

Na lógica de raciocínio de Morin, a ideia de paradoxo está diretamente ligada à questão da ausência de equilíbrio sobre os polos comunicativos, isto é, de um lado, temos a capacidade de nos comunicarmos com muitas pessoas e de inúmeras formas; entretanto, essa comunicação está marcada por um problema muito sério decorrente não apenas da polifonia e das múltiplas interpretaçóes linguísticas, mas da incapacidade de uma escuta empática. Dessa surdez intencional, nascem formas muito deturpadas de compreensão que levam a total incompreensão do outro. Dessa maneira, nasce a percepção de que devemos nos preocupar com este novo saber de caráter compreensivo que emerge das relaçóes humanas. Tal saber deve estar relacionado com uma capacidade dialógica, na qual o falante e o ouvinte se coloquem em uma posição de colaboração. Outrossim, muitos autores dedicaram-se igualmente na busca de um pensamento filosófico capaz de coligar ética e comunicação.

Entre os grandes pensadores da ética contemporânea, podemos citar rapidamente Jürgen Habermas que, ao desenvolver sua Teoria do Agir Comunicativo (2012) apresentou a necessidade de uma visão colaborativa entre os dois polos comunicativos (emissor e receptor), pois o principal problema enfrentado pelo autor alemão, em sua obra, perpassa a total instrumentalização do outro por meio de formas discursivas coercitivas e manipuladoras. Assim, a forma encontrada por Habermas para a superação desses impasses versa sobre a necessidade da busca de consensos por meio de pretensóes de validez que podem ser revisadas por meio da aquiescência do melhor argumento. $\mathrm{O}$ melhor argumento assim não se torna um meio de dominação, mas o resultado de dissensos e consensos alcançados com base na argumentação e na aceitação de que, democraticamente, a dedução apresentada merece o consenso geral dos envolvidos.

Diante disso, nota-se que a questão fundamental a ser tratada por autores como Habermas e Morin não é exatamente a comunicação em si, mas a sua real finalidade e propósito (como vimos em Jonas). Dessa maneira, Morin aponta-nos um problema fulcral acerca dos obstáculos encontrados para a compreensão do outro: 
Os obstáculos exteriores à compreensão intelectual ou objetiva são múltiplos. A compreensão do sentido das palavras de outro, de suas ideias, de sua visáo do mundo está sempre ameaçada por todos os lados:

- Existe o "ruído" que parasita a transmissão da informação, cria o mal-entendido ou o não-entendido. [...] (MORIN, 2002, p. 95)

Dar-se-á destaque a esse ponto específico no pensamento de Morin, pois crê-se que esse ponto é essencial para a "compreensão" do universo político, educativo e democrático de nossa atualidade. $\mathrm{O}$ debate sobre o direito de fala e de apresentação de argumentos, conforme apontado por Habermas, delineia-se pela necessidade de aceitação de que todos os envolvidos podem e devem participar. Organizaçóes mundiais, como a ONU e UNESCO, partem da noção de inclusão de todas as naçóes na medida em que todas estâo em uma posição de igualdade de fala. É evidente que se escolhe um idioma oficial (o idioma inglês) para que a comunicação seja compreendida e assimilada por todos os ouvintes. Entretanto, é preciso considerar que o domínio da fala é maior por parte daquele que é nativo no referido idioma e, muitas vezes, menos por pessoas que não têm o idioma inglês como oficial em seus países de origem. Dessa possível disparidade, nasce o problema da incerteza da apropriação da mensagem comunicada. Essa incerteza, consequentemente, gera ruídos, mal-entendidos e não-entendidos, como nos propóe Morin. Todavia, esse impasse pode ser dirimido na medida em que esforços sejam desprendidos para que a intenção real da comunicação - o entendimento - seja alcançada. A busca pelo entendimento seria um ato deliberado de agir democraticamente.

Reconhecer tal dilema é reconhecer o principal problema da compreensão no mundo que vivemos: o direito de falar e de ser compreendido. Dessa maneira, Morin diz que é preciso o estabelecimento de uma ética da compreensão:

A ética da compreensão é a arte de viver que nos demanda, em primeiro lugar, compreender de modo desinteressado. Demanda grande esforço, pois não pode esperar nenhuma reciprocidade: aquele que é ameaçado de morte por um fanático compreende por que o fanático quer matálo, sabendo que este jamais o compreenderá. [...] É compreender por que e como se odeia e se despreza. A ética da compreensão pede que se compreenda a incompreensão. A ética da compreensão pede que se argumente, que se refute em vez de excomungar e anatematizar. Encerrar na noção de traidor o que decorre da inteligibilidade mais ampla impede que se reconheçam o erro, os desvios, as ideologias, as 
derivas. A compreensão não desculpa nem acusa: pede que se evite a condenação peremptória, irremediável, como se nós mesmos nunca tivéssemos conhecido a fraqueza nem cometido erros. Se soubermos compreender antes de condenar, estaremos no caminho da humanização das relaçôes humanas (MORIN, 2002, p. 99-100).

Diante do exposto por Morin, pode-se inferir que a ideia de responsabilidade apresentada por Jonas se aproxima da ideia de compreensão por Morin. Ao se colocar no mesmo diapasão, a ideia de que nossas açóes presentes devem ponderar com relação aos seus efeitos no futuro, é possível dizer que a compreensão de Morin aponta para a conclusão de que não vale a pena criticarmos a incompreensão se não se sabe ao certo a sua origem. Em Jonas, nota-se uma preocupação com a vida em suas mais variadas manifestaçôes. Em Morin, nota-se, por sua vez, uma necessidade de ampliação da presença do diálogo democrático visando a uma formação humana focada no presente e no futuro. Ao se olhar para trás, não se deve assumir uma certa tristeza ou resignação, mas uma "compreensão". Dessa compreensão, deve surgir uma projeção para o futuro. Por isso, a educação - uma educação pautada em novas formas de comunicação - pode ser vista como o meio mais adequado de emancipação e de transformação dessa nova realidade almejada para o século XXI:

A compreensão é ao mesmo tempo meio e fim da comunicação humana. O planeta necessita, em todos os sentidos, de compreensóes mútuas. Dada a importância da educação para a compreensão, em todos os níveis educativos e em todas as idades, o desenvolvimento da compreensão necessita da reforma planetária das mentalidades; esta deve ser a tarefa da educação do futuro (MORIN, 2002, p. 104).

Essa reforma das mentalidades apresentada por Morin, em outras palavras, imputa a necessidade de se mensurar e equilibrar as formas de comunicação (Habermas) em consonância com a necessidade de um olhar voltado para o futuro da humanidade (Jonas). De qualquer forma, a visão sobre o futuro de toda humanidade perpassa a obrigaçáo ética de um olhar projetado para o amanhã. Essa obrigação será apresentada no próximo item.

\section{O sétimo saber: a ética do gênero humano}

Para Morin (2002), o saber ético é, seguramente, o mais desafiador de todos, se considerarmos que a compreensão recíproca e mútua é o alicerce 
ético das relaçóes educativas entre os seres humanos. Assim sendo, segundo o autor,

[...] individuo/sociedadelespécie são não apenas inseparáveis, mas coprodutores um do outro. Cada um destes termos é, ao mesmo tempo, meio e fim dos outros. Não se pode absolutizar nenhum deles e fazer de um só o fim supremo da tríade; esta é, em si própria, rotativamente, seu próprio fim. Estes elementos náo poderiam, por consequência, ser entendidos como dissociados: qualquer concepção do gênero humano significa desenvolvimento conjunto das autonomias individuais, das participaçóes comunitárias e do sentimento de pertencer à espécie humana. (MORIN, 2002, p. 105-106).

Dessa relação entre os três elementos, que constituem o processo de formação das identidades humanas, Morin cria um conceito muito pontual, a saber, o conceito da antropo-ética. Essa ética está fundada na necessidade de se pensar as açóes humanas segundo a individualidade, a sociedade e a espécie. Porém, é fundamental lembrar que, em Jonas, a discussão ética é ampliada para todos os seres vivos, já que a manutenção da vida depende não apenas da "garantia" da existência humana, mas do planeta como um todo. Nesse quesito, pode-se afirmar que Jonas e Morin não são sectários do mesmo pensamento ético.

Contudo, ao se retomar o pensamento de Morin, vê-se que a antropoética tem um propósito muito claro, a saber, o de estipular uma interrelação da ética com o mundo da democracia e com os debates acerca da complexidade das relaçôes humanas justamente porque a

[...] a democracia não pode ser definida de modo simples. A soberania do povo cidadáo comporta ao mesmo tempo a autolimitação desta soberania pela obediência às leis e a transferência da soberania aos eleitos. A democracia comporta ao mesmo tempo a autolimitaçáo do poder do Estado pela separaçáo dos poderes, a garantia dos direitos individuais e a proteçáo da vida privada. A democracia, evidentemente, necessita do consenso da maioria dos cidadáos e do respeito às regras democráticas. Necessita de que a maioria dos cidadáos acredite na democracia. Mas, do mesmo modo que o consenso, a democracia necessita da diversidade e antagonismos (MORIN, 2002, p. 107-108).

Com base no pensamento de Morin, pode-se apresentar duas perspectivas interessantes de pesquisa, a saber, a do viés do consenso e a do viés do antagonismo. A fim de evitar uma grande prolixidade sobre o tema do 
consenso, é fundamental a apresentação do mundo do antagonismo político apresentado por Chantal Mouffe 5 . Suas ideias permeiam o debate atual sobre a política pelos paradigmas do antagonismo e do agonismo, sendo que, segundo ela, para muitos autores políticos, os antagonismos pertenceriam à uma época já superada ou obsoleta. Para a autora,

os antagonismos pertencem a uma era passada, a um tempo prémoderno, quando as paixôes não tinham ainda sido eliminadas pelo "doce comércio" e substituídas pelo domínio racional dos interesses e pela generalização das identidades "pós-convencionais" (MOUFFE, 2003, p. 12).

Segundo Mouffe, essa visão simplista sobre o antagonismo deve ser melhor compreendida. Inclusive, o termo deve ser pluralizado, pois quando falamos em antagonismos, devemos considerá-los como realidades próprias da vida política, pois é impossível extirpá-los das relaçôes sociais. Considerar que os antagonismos façam parte do passado é o mesmo que considerar que os conflitos na vida pública estejam presentes apenas dentro do contexto das sociedades simples ou "selvagens".

O antagonismo, segundo Mouffe, é inerradicável e deve ser computado em todas as açóes humanas. Isso não significa defender açóes truculentas ou rechaçar o direito de fala (como já apresentado neste trabalho), significa, de todo modo, ritualizar as ações humanas por meio do agonismo, ou seja, apesar do antagonismo sempre existir, é preciso acrescer um outro elemento nesse jogo: o agonismo. Esse elemento ajuda a pressupor que, mesmo que os interesses antagônicos façam parte do jogo das relações políticas, é necessário considerar a presença do outro como "ágon" (adversário), como aquele que disputa, mas que não deve ser visto como intruso, inimigo ou alvo do ódio ou rancor decorrente do antagonismo. Essa visão de Mouffe propõe, para além dos espaços institucionalizados de debates políticos, um agonismo que emana da arte, dos movimentos sociais e do engajamento popular. Segundo ela, é aí que a democracia multipolar, dissensual e inclusiva se encontra:

Vislumbrada a partir da óptica do "pluralismo agonístico", o propósito da política democrática é construir o "eles" de tal modo que não sejam

\footnotetext{
${ }^{5}$ Atualmente, Mouffe é pesquisadora aposentada da Universidade de Westminster, mas ela estuda os problemas e dilemas da política mundial de maneira mais enfática desde 1985, quando publicou, em parceria com seu falecido esposo Ernesto Laclau (1935-2014), o livro Hegemony and Socialist Strategy: Towards a Radical Democratic Politics (2014). Essa parceria resultou em obras dinâmicas que abordam as vicissitudes decorrentes do pensamento liberal e neoliberal em um mundo considerado pós-moderno e pós-marxista.
} 
percebidos como inimigos a serem destruídos, mas como adversários, ou seja, pessoas cujas ideias são combatidas, mas cujo direito de defender tais ideias não é colocado em questão. [...] Um adversário é um inimigo, mas um inimigo legítimo, com quem temos alguma base comum, em virtude de termos uma adesão compartilhada aos princípios éticos-políticos da democracia liberal: liberdade e igualdade. [...] Aceitar a visão do adversário significa passar por uma mudança radical de identidades políticas. É mais uma espécie de conversão do que um processo de persuasáo racional [...]. Pactos [compromises] certamente são também possíveis; eles são parte integrante do cotidiano da política, mas deveriam ser vistos como interrupçóes temporárias de uma confrontação contínua. (MOUFFE, 2005, p. 174).

Nesse contexto, pode-se inferir que a ética do gênero humano de Morin coaduna com a ideia de Mouffe na medida em que ambos os autores se mostram interessados em formas de organização da vida social com foco na democracia, pois pode-se ver com grande clareza, a preocupação que os dois autores têm com o diálogo entre todos os aspectos da vida coletiva. Assim sendo, Morin diz que [...] todas as características importantes da democracia têm um caráter dialógico que une de modo complementar termos antagônicos: consenso/conflito, liberdadeligualdadelfraternidade, comunidade nacionallantagonismos sociais e ideológicos. [...] (MORIN, 2002, p. 109).

Todavia, o problema mais sério repousa na incapacidade de diálogo entre os polos antagônicos. Como viu-se com Mouffe, o antagonismo nunca será totalmente erradicado, mas necessita de ritualização. Dessa maneira, precisa-se de uma nova ética, de uma ética capaz de abarcar, embarcar e abraçar o planeta inteiro, o que pode ser apreendido, a partir das ideias apontadas por Morin, nas últimas páginas do seu livro Os Sete Saberes necessários à Educação do Futuro:

A Humanidade deixou de constituir uma noção apenas biológica e deve ser, ao mesmo tempo, plenamente reconhecida em sua inclusão indissociável na biosfera: a Humanidade deixou de constituir uma noção sem raízes: está enraizada em uma "Pátria", a Terra, e a Terra é uma Pátria em perigo. A Humanidade deixou de constituir uma noção abstrata: é realidade vital, pois está, doravante, pela primeira vez, ameaçada de morte; a Humanidade deixou de constituir uma noçáo somente ideal, tornou-se uma comunidade de destino, e somente a consciência desta comunidade pode conduzi-la a uma comunidade de vida; a Humanidade é, daqui em diante, sobretudo uma noção ética: é 
o que deve ser realizado por todos e em cada um (MORIN, 2002, p. 114).

Assim sendo, vemos que entre Morin e Jonas e muitos autores contemporâneos, há fissuras que são preenchidas por meio da complementaridade entre educação, sustentabilidade, responsabilidade, comunicação, ação e antagonismos/agonismos. Todos eles, ao fim e ao cabo, mostram as possibilidades que os seres humanos têm para construir pontes de diálogo democrático. São saberes que estão dados e que precisam se colocar em uma posição de transdisciplinaridade justamente porque, como vimos com nossos autores, não há saberes em ascensão ou em declínio, há apenas o exercício pendular que oscila entre os dissensos (divergências e oposiçôes sobre pontos de vista diferentes) e os consensos (visão ética e democrática sobre o mundo) e que o meio-termo entre eles está nos interstícios que os coligam.

\section{Consideraçóes finais}

Este artigo ensaístico buscou problematizar as tendências dos processos educativos que ainda estáo pautados em uma organização disciplinar, com foco no ensino de conteúdos que se distanciam das questôes sociais. Nesse contexto, foram apresentados dois princípios basilares: a responsabilidade ética, de Hans Jonas e dois saberes necessários à vida humana propostos por Edgar Morin: ensinar a compreensão e a ética do gênero humano.

Desse modo, este artigo, ao tomar como referência a teoria de Hans Jonas, buscou analisar como as questóes ligadas à vida moderna, de modo especial, a técnica/tecnologia afeta "a natureza do nosso agir, até que ponto ela torna o agir sob seu domínio algo do que existiu ao longo dos tempos (JONAS, 2006, p. 29). Desse modo, ao se abordar a questão das técnicas/tecnologias é preciso problematizar o novo contexto que se instaura: impactos positivos e impactos negativos para a vida humana. Nessa problematização, o processo educativo, na perspectiva de uma educação voltada para a responsabilidade ética, pode iluminar modos de pensar e agir, ou seja, a gestão da vida no mundo Assim, "a ética da responsabilidade poderá ser um bom instrumento na valorização da vida, do meio ambiente e de tudo que deve existir (ZANCANARO, 2011, p. 1). Desse modo, a educação pode tematizar questóes que afetam a qualidade de vida, a sustentabilidade e justiça social.

No que diz respeito aos dois saberes propostos por Morin selecionados para discussão, pode-se considerar que esses saberes são essenciais 
para a promoção da responsabilidade ética, proposta por Hans Jones. Assim, em relação ao saber "ensinar a compreensão", é possível antever uma ampliação do termo compreensão para além da dimensão cognitiva, uma vez que insere a compreensão entre as pessoas como condição e garantia da solidariedade intelectual e moral da humanidade, viabilizando a justiça social. Em relação ao saber ético proposto por Morin, articulado às ideias de Mouffe, é possível considerar que a existência de dissensos e consensos pode contribuir para que a formação humana seja mais plural, mais sensível e mais respeitosa.

A partir do exposto, podemos considerar que é compreensível que os problemas presentes no cotidiano social e que preocupam a sociedade mundial sejam tomados como ponto de partida para um redimensionamento das práticas educativas. Nesse ponto, cabe destacar uma questão nevrálgica, ou seja, as propostas de solução dos problemas advêm da ciência, mas, com a ciência, emerge também a incerteza em relação ao que acontece com os valores e a ética humanos, se eles foram levados em consideração ou não. A responsabilidade do/com o ser humano deve estar presente nos diferentes contextos sociais, com vistas a promoção da paz, da consciência moral e da justiça social. Caso contrário, os avanços científicos e tecnológicos não serão utilizados para a melhoria da qualidade de vida e para a evolução da humanidade. Portanto, é importante considerar que um ponto de vista de uma ciência não possui todos os elementos para poder explicar todo o conhecimento existente no globo, e que nem todas as explicaçóes científicas vão permanecer válidas para sempre. Nesse sentido, educar na perspectiva da responsabilidade ética implica que compreender é também aprender e reaprender incessantemente. A ética da compreensão "pede que se argumente, que se refute em vez de excomungar e anatematizar” (MORIN, 2001, p. 100), descarta a acusação, opressão. Dessa forma, a Educação constitui um processo integral de formação humana, pois cada ser humano precisa construir o seu modo de vida, tendo por base o compromisso ético com a natureza, a responsabilidade por suas açôes e a compreensão das potencialidades de promoção da justiça social por parte de cada cidadáo.

\section{Referências}

CANIVEZ, P. Educar o Cidadão? Tradução de Estela dos Santos Abreu e Claudio Santoro. Campinas-SP: Papirus, 1991.

GONZÁLEZ VELASCO, J. M. Pensamento religado: ligar para religar. La Paz: Prisa, 2018. 
GONZÁLEZ VELASCO, J. M. Religaje educativo: espacio-tiempo. La Paz: Prisa, 2017.

HABERMAS, J. Teoria do Agir Comunicativo 1: Racionalidade da Ação e Racionalização Social. Tradução de Paulo Astor Soethe. Revisão de tradução: Flávio Beno Siebeneichler. São Paulo: Editora WMF Martins Fontes, 2012.

JONAS, H. O princípio responsabilidade: ensaio de uma ética para a civilização tecnológica. Tradução de Marjane Lisboa e Luiz Barros Montez, Rio de Janeiro: Contraponto. Ed. PUC-Rio, 2006.

LACLAU, C.; MOUFFE, C. Hegemony and Socialist Strategy: Towards a Radical Democratic Politics. Second ed., Verso, 2014. (ebook).

MORIN, E. Os Sete Saberes necessários à Educação do Futuro. Tradução de Catarina Eleonora F. da Silva e Jeanne Sawaya. Revisão técnica de Edgard de Assis Carvalho. 5. ed. São Paulo: Cortez, Brasília-DF - UNESCO, 2002.

MOUFFE, C. Democracia, cidadania e a questão do pluralismo. Revista Política e Sociedade, Florianópolis-SC, v.2, n. 3, p. 11-26, Out. 2003.

MOUFFE, C. Por um modelo agonístico de democracia. Trad. de Pablo Sanges Ghetti. Revista de Sociologia e política, Curitiba, n. 25, p. 165-175, junho de 2005. (UFPR).

OLIVEIRA, J. R. Por que uma ética do futuro precisa de uma fundamentação ontológica segundo Hans Jonas. Rev. Filos., Aurora, Curitiba, v. 24, n. 35, p. 387-416, jul./dez. 2012.

PETRAGLIA, I. Educação complexa para uma nova política de civilização. Educar, Curitiba, v. 32, p. 29-41, 2008.

PETRAGLiA, I. Pensamento complexo e educação. São Paulo: Livraria da Física, 2013.

PIMENTA, A. C. Resenha: Introdução ao pensamento complexo de Edgar Morin. Revista Cientifica da FHO/UNIARARAS, [s.l.], v. 1, n. 2, p. 33-37, 2013.

RANCIĖRE, J. O dissenso. In: NOVAES, A. (org.) Crise da Razão. Rio de Janeiro: Cia das Letras, 1996.

ZANCANARO, L. Por uma ética do cuidado e da responsabilidade. Revista do IHU online, agosto de 2011. 
ZWIEREWICZ, M.; TORRE, S. (org.). Uma escola para o século XXI: escolas criativas e resiliência na educação. Florianópolis: Insular, 2009.

ZWIEREWICZ, M. (org.). Criatividade e inovação no Ensino Superior: experiências latino-americanas e europeias em foco. Blumenau: Nova Letra, 2013. p. 139-162.

ZWIEREWICZ, M. Programa de Formação-Ação em Escolas Criativas: matizes da pedagogia ecossistêmica na formação de docentes da Educação Básica. In: DITTRICH, M. G. et al. (Org.). Políticas Públicas na contemporaneidade: olhares cartográficos temáticos. Itajaí: Univali, 2017. p. 217-231.

Recebido em: 19 ago. 2020

Aceito em: 02 set. 2020 